Research

Open Access

\title{
Factors associated with septic shock and mortality in generalized peritonitis: comparison between community-acquired and postoperative peritonitis
}

\author{
Florence C Riché1, Xavier Dray², Marie-Josèphe Laisné1, Joaquim Matéo1, Laurent Raskine³, Marie-
} José Sanson-Le Pors ${ }^{3}$, Didier Payen1, Patrice Valleur ${ }^{4}$ and Bernard P Cholley ${ }^{5,6}$

\begin{abstract}
1Department of Anesthesiology and Intensive Care, Hôpital Lariboisière, Assistance Publique-Hôpitaux de Paris (AP-HP), 2 rue Ambroise Paré, Paris 75010, France

2Department of Gastroenterology, Hôpital Lariboisière, Assistance Publique-Hôpitaux de Paris (AP-HP), 2 rue Ambroise Paré, Paris 75010, France ${ }^{3}$ Department of Bacteriology-Virology, Hôpital Lariboisière, Assistance Publique-Hôpitaux de Paris (AP-HP), 2 rue Ambroise Paré, Paris 75010, France

${ }^{4}$ Department of Digestive Surgery, Hôpital Lariboisière, Assistance Publique-Hôpitaux de Paris (AP-HP), 2 rue Ambroise Paré, Paris 75010, France 5Department of Anesthesiology and Intensive Care, Hôpital Européen Georges Pompidou, Assistance Publique-Hôpitaux de Paris (AP-HP), 20 rue Leblanc, Paris 75015 , France

6Université Paris-Descartes, Faculté de Médecine, 15 rue de l'Ecole de Médecine, Paris 75006, France
\end{abstract}

Corresponding author: Florence C Riché, florence.riche@lrb.aphp.fr; Bernard P Cholley, bernard.cholley@egp.aphp.fr

Received: 11 Jun 2009 Accepted: 24 Jun 2009 Published: 24 Jun 2009

Critical Care 2009, 13:R99 (doi:10.1186/cc7931)

This article is online at: http://ccforum.com/content/13/3/R99

(c) 2009 Riché et al.; licensee BioMed Central Ltd.

This is an open access article distributed under the terms of the Creative Commons Attribution License (http://creativecommons.org/licenses/by/2.0), which permits unrestricted use, distribution, and reproduction in any medium, provided the original work is properly cited.

\begin{abstract}
Introduction The risk factors associated with poor outcome in generalized peritonitis are still debated. Our aim was to analyze clinical and bacteriological factors associated with the occurrence of shock and mortality in patients with secondary generalized peritonitis.

Methods This was a prospective observational study involving 180 consecutive patients with secondary generalized peritonitis (community-acquired and postoperative) at a single center. We recorded peri-operative occurrence of septic shock and 30-day survival rate and analyzed their associations with patients characteristics (age, gender, SAPS II, liver cirrhosis, cancer, origin of peritonitis), and microbiological/mycological data (peritoneal fluid, blood cultures).
\end{abstract}

Results Frequency of septic shock was $41 \%$ and overall mortality rate was $19 \%$ in our cohort. Patients with septic shock had a mortality rate of $35 \%$, versus $8 \%$ for patients without shock. Septic shock occurrence and mortality rate were not different between community-acquired and postoperative peritonitis. Age over 65 , two or more microorganisms, or anaerobes in peritoneal fluid culture were independent risk factors of shock. In the subgroup of peritonitis with septic shock, biliary origin was independently associated with increased mortality. In addition, intraperitoneal yeasts and Enterococci were associated with septic shock in community-acquired peritonitis. Yeasts in the peritoneal fluid of postoperative peritonitis were also an independent risk factor of death in patients with septic shock.

Conclusions Unlike previous studies, we observed no difference in incidence of shock and prognosis between community-acquired and postoperative peritonitis. Our findings support the deleterious role of Enterococcus species and yeasts in peritoneal fluid, reinforcing the need for prospective trials evaluating systematic treatment against these microorganisms in patients with secondary peritonitis.

\section{Introduction}

Septic shock is a frequent complication of generalized peritonitis, which can result in multiple organ failure and sometimes death [1]. In secondary peritonitis [2], postoperative peritonitis is commonly thought to be more severe than communityacquired peritonitis [3-5]. The reasons advocated to support 
this include the immune suppression related to initial surgery $[6,7]$, a loss of the normal, physiologic bacterial clearance from the peritoneum [8], foreign material within the peritoneal cavity (blood, bile), and inadequate initial empirical antibiotic treatment in postoperative peritonitis due to increased frequency of resistant pathogens [3]. Although commonly believed, the worse prognosis associated with postoperative peritonitis is supported by limited data [9]. Microbiologic differences between postoperative and community-acquired peritonitis have also been reported. Enterococci are more frequently isolated from peritoneal fluid of postoperative peritonitis [4], but the deleterious role of these microorganisms in comparisons to other species is still under debate. Yeasts, on the other hand, have been shown to increase the risk of death in postoperative peritonitis [10]. However, the administration of specific treatment aimed at Enterococci or Candida isolated from polymicrobial intra-abdominal infection remains controversial [11].

The goal of this prospective observational study was to analyze clinical and bacteriologic factors associated with the occurrence of shock and mortality in patients with secondary generalized peritonitis. In addition, we studied the association between shock, mortality, and bacteriologic features among community-acquired and postoperative peritonitis.

\section{Materials and methods}

Consecutive adult patients admitted to our surgical intensive care unit after being operated on for secondary generalized peritonitis were screened over a period of six years. Patients were included if they were over 18 years of age and if the diagnosis of secondary generalized peritonitis (communityacquired and postoperative peritoneal infection) was confirmed surgically. Patients were excluded if they had secondary peritonitis as a result of penetrating trauma, tertiary peritonitis defined as recurrent postoperative peritonitis, primary peritonitis (medical cause of intra-abdominal infection that did not require surgery), or if they had received steroids as part of their treatment. This study was purely observational and therefore our Institutional Review Board waived the need for informed consent.

\section{Diagnosis and surgical management of generalized peritonitis}

In all cases the origin of sepsis was abdominal and required laparotomy. After incision and confirmation de visu of intraabdominal infection involving the whole peritoneal cavity, peritoneal fluid was sampled for microbiology and abundant peritoneal lavage was then performed using sterile isotonic sodium chloride solution. No patients underwent open-wound management and the abdomen was not irrigated after surgery. Ostomies were systematically preferred to primary anastomosis. We did not perform planned re-laparotomy, and patients were re-operated on-demand exclusively.

\section{Septic shock definition}

Septic shock was defined according to the criteria of the Critical Care Medicine Consensus Conference [12] as: systemic inflammatory response as defined by two or more of the following temperature higher than $38.5^{\circ} \mathrm{C}$ or lower than $35^{\circ} \mathrm{C}$, heart rate higher than 90 beats $/ \mathrm{min}$, respiratory rate higher than 20 breaths $/ \mathrm{min}$ or partial pressure of arterial carbon dioxide $\left(\mathrm{PaCO}_{2}\right)$ less than $32 \mathrm{mmHg}$ or need for mechanical ventilation, white blood cell count higher than $12.0 \times 10^{9} / \mathrm{l}$ or less than $4.0 \times 10 \% /$ or containing more than $10 \%$ immature forms; evidence of a nidus of infection; and systolic blood pressure less than $90 \mathrm{mmHg}$ (for at least one hour) despite adequate fluid replacement and infusion of vasopressor associated with at least two signs of perfusion abnormality (lactic acidosis, oliguria, abrupt alteration in mental status).

Septic shock started either less than 24 hours before, during, or up to 24 hours after surgical intervention.

\section{Microbiologic sampling}

Peritoneal fluid was harvested for culture immediately after opening the peritoneal cavity. Three blood samples were also systematically collected for cultures within the first 24 hours following admission. Routine microbiologic techniques were applied for microorganism culture and identification.

\section{Antibiotic therapy}

The patients received antibiotic therapy prior to anesthesia induction according to our institutional protocols. For community-acquired peritonitis, we used amoxicillin-clavulanic acid (2 g-200 mg) associated with gentamycin $(3 \mathrm{mg} / \mathrm{kg})$ at the time of induction of anesthesia, followed by amoxicillin-clavulanic acid (1 g-200 mg every every hours) and gentamycin (3 mg/ $\mathrm{kg} /$ day) during five days. For postoperative peritonitis, we used piperacillin-tazobactam $(4 \mathrm{~g})$ with gentamycin $3 \mathrm{mg} / \mathrm{kg}$ at induction, and piperacillin-tazobactam ( $4 \mathrm{~g}$ every six hours) associated with gentamycin ( $3 \mathrm{mg} / \mathrm{kg}$ daily) for five days. If a patient was allergic, we used gentamycine $(3 \mathrm{mg} / \mathrm{kg} /$ day $)$ associated with ornidazole $(1 \mathrm{~g})$ for five days. Antibiotic therapy was then adjusted to germ sensitivity, as soon as available.

\section{Data collection}

We collected demographic and clinical data including age, gender, simplified acute physiology score (SAPS) II, existing liver cirrhosis or cancer, origin of peritonitis (biliary, upper-mesocolic, and under-mesocolic). We estimated whether the delay between onset of symptoms, presumably related to peritonitis, and surgical intervention was less or greater than 24 hours. Microbiologic and mycologic results of all cultures (peritoneal fluid collected during surgery and blood samples obtained within the first 24 hours) were recorded. Peri-operative occurrence of septic shock and 30-day survival rate were analyzed. 


\section{Statistical analysis}

All data were entered into a computer-based data file. Statistical analyses were performed using Stata ${ }^{\circledR} 10$ (StataCorp LP, College Station, TX, USA). Results are reported as mean \pm standard deviation. Significance of the differences for continuous variables was calculated using Student's t-test. Qualitative data were compared using chi-squares test and Fisher's exact test as appropriate.

\section{Septic shock}

The null hypothesis tested was that the risk of septic shock was the same in all groups. Associations (chi-squared test) and interactions (Mantel-Haenszel chi-squared test) were tested for all variables. For each risk factor assessed, an estimate of the odds ratio (OR), its exact Fisher 95\% confidence interval $(\mathrm{Cl})$, and $P$ value were calculated. Based on the results of the univariate analysis, a step-down logistic regression was conducted, adjusting for age, gender, origin of generalized peritonitis (colon, biliary tract), type of secondary generalized peritonitis (community acquired or postoperative), comorbidity (cancer, cirrhosis), and microbiologic features (bacteremia, Gram-negative bacilli, anaerobes, Enterococcus or yeasts in the peritoneal fluid) [13].

\section{Survival analysis}

The null hypothesis tested was that the risk of death of any cause within 30 days following surgery is the same in all groups. Kaplan-Meier curves were calculated to estimate the time to death. Log-rank tests were performed to assess risk factors for death. Relative risk (RR) of death was calculated for each variable with its $95 \% \mathrm{Cl}$ and $P$ value. The hypothesis of proportionality of risk over time was assessed for each covariate using graphical method and, when needed, by testing the statistical significance of an interaction term between the explanatory variable and time [14]. Based on the results of the univariate analysis, multivariate Cox proportional hazards models were applied, adjusting for gender, SAPS II, type of secondary generalized peritonitis (community-acquired or postoperative), and biliary origin of generalized peritonitis.

\section{Results}

One hundred and eighty patients with secondary peritonitis were prospectively studied. Patients' characteristics are presented in Table 1. The origin of peritonitis is described in Table 2. Patients were separated into two groups according to the occurrence of septic shock. Seventy four patients (41\%) developed perioperative septic shock $(<24$ hours before, during, or up to 24 hours after surgical intervention). The clinical characteristics, outcome, and bacteriologic data of patients with and without septic shock are presented in Table 3. Multivariate analysis identified three independent factors related to the occurrence of septic shock: age over 65 years, two or more microorganisms, or anaerobes in the peritoneal fluid (Table 4). Mortality at day-30 was $8 \%$ in patients who did not develop septic shock, and $35 \%$ in patients with septic shock (OR $=4.11,95 \% \mathrm{Cl}=1.78$ to $9.48, P=0.0003$ ). Because few deaths were observed at day 30 in patients with no septic shock (9 events out of 106 patients), survival analysis could not be conducted with sufficient power in this group. Survival analysis was therefore performed only in the sub-group of patients with septic shock. Risk factors for mortality in patients with septic shock are presented in Table 5. Multivariate analysis identified two independent risk factors associated with death in the subgroup of patients with septic shock: SAPS II (adjusted OR $=1.02 ; 95 \% \mathrm{Cl}=1.0$ to $1.04, P=0.04$ ) and biliary origin of peritonitis (adjusted $\mathrm{OR}=3.50 ; 95 \% \mathrm{Cl}=$ 1.09 to $11.70, P=0.03$ ). Survival curves according to biliary or non-biliary origin of peritonitis is depicted in Figure 1.

\section{Comparison of community-acquired and postoperative peritonitis}

There were 24 deaths among the 112 patients with community-acquired peritonitis ( $21 \%$ mortality rate) and 11 deaths among the 68 patients with postoperative peritonitis $(16 \%$ mortality rate). The probability of survival was $0.81(95 \% \mathrm{Cl}=$ 0.72 to 0.87$)$ for community-acquired and $0.89(95 \% \mathrm{Cl}=$ 0.79 to 0.94 ) for postoperative peritonitis. Thus, survival rates at day 30 were not statistically different for communityacquired and postoperative peritonitis (RR $=0.55,95 \% \mathrm{Cl}=$ 0.24 to $1.27, P=0.16$ ). Forty-two patients with community-

Table 1

\section{Patients characteristics}

Age (years)

Female/male

SAPS ॥

Mortality

Cirrhosis

Cancer
$62 \pm 18$ (19 to 100$)$

$83 / 97$

$37 \pm 18$ (9 to 103 )

$19 \%$ (35 out of 180 patients)

6

45

$112 / 68$

Results presented as mean \pm standard deviation.

SAPS = simplified acute physiology score. 
Table 2

\begin{tabular}{lc}
\hline Origin of peritonitis & \\
\hline \multicolumn{1}{c}{ Source of infection } & Number of patients \\
\hline Colon & 69 \\
Gastro-duodenum & 39 \\
Post-duodenal small bowel & 33 \\
Biliary tract & 14 \\
Appendix & 14 \\
Other & 11 \\
\hline
\end{tabular}

acquired peritonitis (37\%) developed septic shock compared with $32(47 \%)$ among patients with postoperative peritonitis $(P=0.26)$. The proportion of patients operated less than 24 hours after the onset of symptoms was not different between community-acquired and postoperative peritonitis (54\% vs. $49 \%$, respectively; $P=0.61$ ).

Patients who developed septic shock were significantly older than patients with no septic shock in the community-acquired peritonitis group (67 \pm 17 vs. $59 \pm 19$ years, $P=0.03$ ) and in the postoperative peritonitis group ( $68 \pm 11$ vs. $55 \pm 18$ years, $P=0.001$ ). Bacteriologic features of peritoneal fluid culture according to type of generalized peritonitis and occurrence of septic shock are presented in Figures 2 and 3. In both types of generalized peritonitis, anaerobes were found to be significantly associated with septic shock $(P=0.02)$. Both types of peritonitis exhibited microbiologic differences: Enterococcus species and yeasts isolated in the culture of peritoneal fluid were significantly associated with the development of septic shock in patients with community-acquired generalized peritonitis, but not postoperative peritonitis. The RR of death was higher if yeasts were cultured from peritoneal fluid of postoperative peritonitis $(\mathrm{RR}=4.28,95 \% \mathrm{Cl}=1.02$ to $18.04, P=$ 0.03; Figure 4, Table 6).

\section{Discussion}

We prospectively studied a cohort of 180 consecutive patients operated on for generalized peritonitis. The frequency of septic shock was $41 \%$ and mortality rate was $19 \%$. Age over 65 years, two or more microorganisms, or anaerobes in peritoneal fluid culture were independent risk factors of shock. Septic shock occurrence was no different between patients with community-acquired and postoperative peritonitis. Mortality rate was also comparable between these two groups. In the subgroup of patients with peritonitis with septic shock, biliary origin was independently associated with increased mortality. Yeast in peritoneal fluid of postoperative peritonitis was also an independent risk factor of death in patients with septic shock.

Table 3

\begin{tabular}{|c|c|c|c|}
\hline & $\begin{array}{c}\text { GP with SS } \\
\mathrm{n}=74(41 \%)\end{array}$ & $\begin{array}{l}\text { GP without SS } \\
n=106(59 \%)\end{array}$ & $P$ \\
\hline Gender female/male & $30 / 44$ & $53 / 53$ & ns \\
\hline Age (years) & $67 \pm 15$ & $58 \pm 19$ & 0.0004 \\
\hline SAPS II & $51 \pm 16$ & $27 \pm 13$ & 0.0001 \\
\hline Cancer & $27(36 \%)$ & $18(16 \%)$ & 0.003 \\
\hline Cirrhosis & $4(0.05 \%)$ & $2(0.02 \%)$ & ns \\
\hline Postoperative/community-acquired & $42 / 32$ & $70 / 36$ & $\mathrm{~ns}$ \\
\hline Upper/under mesocolic & $22 / 52$ & $40 / 66$ & ns \\
\hline Biliary origin & $6(8 \%)$ & $8(7 \%)$ & ns \\
\hline Bacteremia & $19(26 \%)$ & $6(6 \%)$ & 0.0001 \\
\hline Monomicrobial or sterile/Polymicrobial ${ }^{1}$ peritoneal culture & $23 / 51$ & $68 / 38$ & 0.0001 \\
\hline \multicolumn{4}{|l|}{ Culture of peritoneal fluid number of patients (\%): } \\
\hline Anaerobes & $24(32 \%)$ & $10(9 \%)$ & 0.0001 \\
\hline Escherichia coli & $26(35 \%)$ & $38(35 \%)$ & $\mathrm{ns}$ \\
\hline Enterococcus species & $14(19 \%)$ & $13(12 \%)$ & ns \\
\hline Yeasts & $12(16 \%)$ & $11(10 \%)$ & ns \\
\hline
\end{tabular}

${ }_{1}$ Polymicrobial if $\geq 2$ germs in peritoneal fluid culture. Univariate analysis (Log rank test). $\mathrm{GP}=$ generalized peritonitis; $\mathrm{ns}=$ not significant; $\mathrm{SS}=$ septic shock. 
Table 4

\begin{tabular}{lccc}
\hline \multicolumn{2}{l}{ Independent risk factors for the development of septic shock in generalized peritonitis } & \\
\hline & Adjusted odds ratio & $95 \%$ confidence interval & $P$ \\
\hline Age $>65$ years & 2.6 & 1.22 to 5.54 & 1.48 to 7.87 \\
$\geq 2$ germs in peritoneal fluid & 3.41 & 1.07 to 7.21 & 0.013 \\
Anaerobes in peritoneal fluid & 2.78 & 0.96 to 4.98 & 0.004 \\
Cancer & 2.18 & 0.87 to 5.32 & 0.06 \\
Bacteremia & 2.16 & 0.09 \\
\hline
\end{tabular}

Multivariate analysis (Cox model).

\section{Risk factors of septic shock}

Not surprisingly, age was independently associated with shock and mortality in our patients with peritonitis. It is established that the incidence of septic shock as well as mortality rate increases with age, regardless of infection source [15]. The alteration of innate and acquired immunity in elderly patients is well recognized: decreased phagocytosis and chemotactism of polymorphonuclear cells associated with reduced activity of natural killer cells may, in part, contribute to explain the susceptibility to infection in this population $[16,17]$. Poor nutritional status and limited physiologic reserves fre- quently observed in elderly patients may also contribute as well [18].

In our study, two or more microorganisms in peritoneal fluid culture were associated with a higher incidence of septic shock. This was especially obvious in the sub-group of patients with community-acquired peritonitis $(P=0.0001)$. The infectious peritoneal insult triggers local and systemic inflammatory responses leading to shock [19-21]. More than 30 years ago, Onderdonk and colleagues introduced the concept of 'bacterial synergism' suggesting that the association of

Table 5

Relative risk of death and confidence intervals for patients with generalized peritonitis and septic shock

\begin{tabular}{|c|c|c|c|}
\hline & Relative risk & $95 \%$ confidence interval & $P$ \\
\hline Age $>65$ years & 1.79 & 0.64 to 5.01 & 0.26 \\
\hline Female & 1.76 & 0.66 to 4.69 & 0.25 \\
\hline SAPS II & 1.03 & 1.00 to 1.06 & 0.03 \\
\hline Postoperative/community-acquired & 0.45 & 0.17 to 1.20 & 0.10 \\
\hline$\geq 2$ germs in peritoneal fluid & 0.90 & 0.32 to 2.56 & 0.85 \\
\hline Under vs. upper mesocolic & 0.72 & 0.28 to 1.84 & 0.49 \\
\hline Biliary origin of peritonitis & 4.75 & 1.45 to 15.57 & $<0.005$ \\
\hline Colonic origin of peritonitis & 1.22 & 0.50 to 3.01 & 0.66 \\
\hline Cancer & 1.54 & 0.62 to 3.83 & 0.35 \\
\hline Cirrhosis & 0.94 & 0.12 to 7.35 & 0.95 \\
\hline Hepatic metastasis & 0.94 & 0.12 to 7.35 & 0.95 \\
\hline Gram-negative bacilli in peritoneal fluid & 1.41 & 0.50 to 3.96 & 0.51 \\
\hline Escherichia Coli in peritoneal fluid & 0.66 & 0.26 to 1.70 & 0.39 \\
\hline Gram-positive cocci in peritoneal fluid & 0.97 & 0.38 to 2.48 & 0.95 \\
\hline Enterococcus in peritoneal fluid & 0.84 & 0.27 to 2.56 & 0.75 \\
\hline Anaerobes in peritoneal fluid & 0.88 & 0.33 to 2.35 & 0.81 \\
\hline Bacteremia & 1.06 & 0.91 to 3.01 & 0.38 \\
\hline Yeasts & 1.23 & 0.40 to 3.75 & 0.71 \\
\hline
\end{tabular}

Univariate analysis (Log rank test). SAPS = simplified acute physiology score. 


\section{Figure 1}

Survival according to biliary or non-biliary origin of peritonitis with shock (\%)

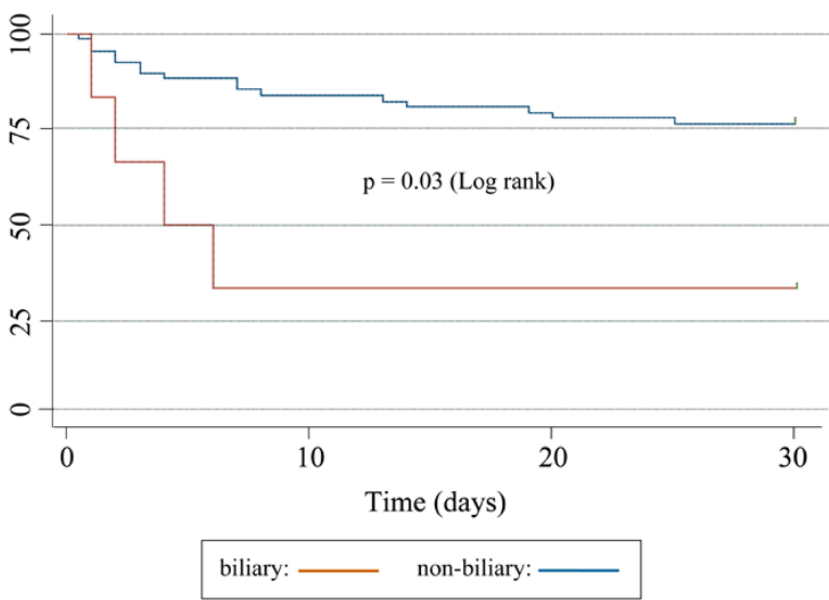

Survival according to biliary or non-biliary origin of peritonitis with septic shock.

Escherichia coli, Enterococci, and Bacteroides fragilis in experimental peritonitis was always lethal [22]. We also observed that shock was more frequent when anaerobes were cultured from peritoneal fluid in all types of generalized peritonitis. The virulence of anaerobes is well recognized, and species like Bacteroides have been shown to produce factors that directly inhibit polymorphonuclear leukocyte functions in humans [23-26].

We observed a mortality rate of $19 \%$ in our cohort, a figure that is in the lower part of the range (16 to 50\%) reported in the literature $[2,3]$. Septic shock is a major risk factor for death $[15,27,28]$ as corroborated by the present findings: mortality was 35\% among patients with septic shock, while it was only $8 \%$ in patients without septic shock $(P=0.0003)$. Because the incidence of death was low in the subgroup of patients without shock, we could not carry out proper statistical analysis in this population. Among patients with septic shock, SAPS II and biliary origin of peritonitis were independent risk factors for mortality. Bile, per se, triggers a massive inflammatory response within the peritoneum, involving polymorphonuclear and mesothelial cells [29]. In addition to their direct chemical effect on the peritoneum, biliary salts contribute to release large amounts of endotoxin from the membranes of Gram-negative microorganisms in the peritoneal cavity and the portal vein [30]. The direct role of bile in worsening prognosis of peritonitis has also been recognized previously [31]. No patient with biliary peritonitis had positive yeast cultures, suggesting that these risk factors are probably not linked.

\section{Community-acquired versus postoperative peritonitis}

We did not observe any difference between patients with community-acquired and postoperative peritonitis regarding the occurrence of septic shock or mortality rate. This was rather surprising because it is usually admitted that postoperative peritonitis carries a worst prognosis $[3,4]$. The delay to surgery was not a confounding factor because the proportion of patients operated on early ( $\leq 24$ hours) or late ( $>24$ hours) was similar between these two groups. Factors that have been involved in increased severity for postoperative peritonitis include postoperative immune suppression $[6,7]$, and inappropriate antibiotic therapy related to increased frequency of multiple resistance bacterial strains [3,32]. Very little data are available regarding microbiologic findings in patients with severe community-acquired peritonitis. Two studies observed that $E$. Coli, anaerobes and Enterococcus were the microorganisms most frequently isolated [5,33], but this was not different from less severe peritonitis [34]. Our observations are quite different because anaerobes, Enterococcus species, or yeasts were more often associated with septic shock in patients with community-acquired peritonitis. The severity of Enterococcus faecalis has been previously reported in an

Table 6

Relative risk of death at day 30 and $95 \%$ confidence intervals of patients with peritonitis according to the type of organism cultured from peritoneal fluid (Mantel-Haenszel test, controlling for time)

\begin{tabular}{|c|c|c|c|}
\hline & Relative risk & $95 \%$ confidence interval & $\mathrm{P}$ \\
\hline \multicolumn{4}{|c|}{ Community-acquired peritonitis } \\
\hline Yeasts & 1.72 & 0.57 to 5.16 & 0.33 \\
\hline Enterococcus species & 1.05 & 0.24 to 4.58 & 0.94 \\
\hline Anaerobes & 1.83 & 0.66 to 5.10 & 0.24 \\
\hline \multicolumn{4}{|l|}{ Postoperative peritonitis } \\
\hline Yeasts & 4.28 & 1.02 to 18.04 & 0.031 \\
\hline Enterococcus species & 1.47 & 0.35 to 6.22 & 0.60 \\
\hline Anaerobes & 0.50 & 0.06 to 4.11 & 0.51 \\
\hline
\end{tabular}


Germs from peritoneal fluid culture in community-acquired peritonitis

septic shock: $\mathrm{n}=42$, no septic shock: $\mathrm{n}=70$

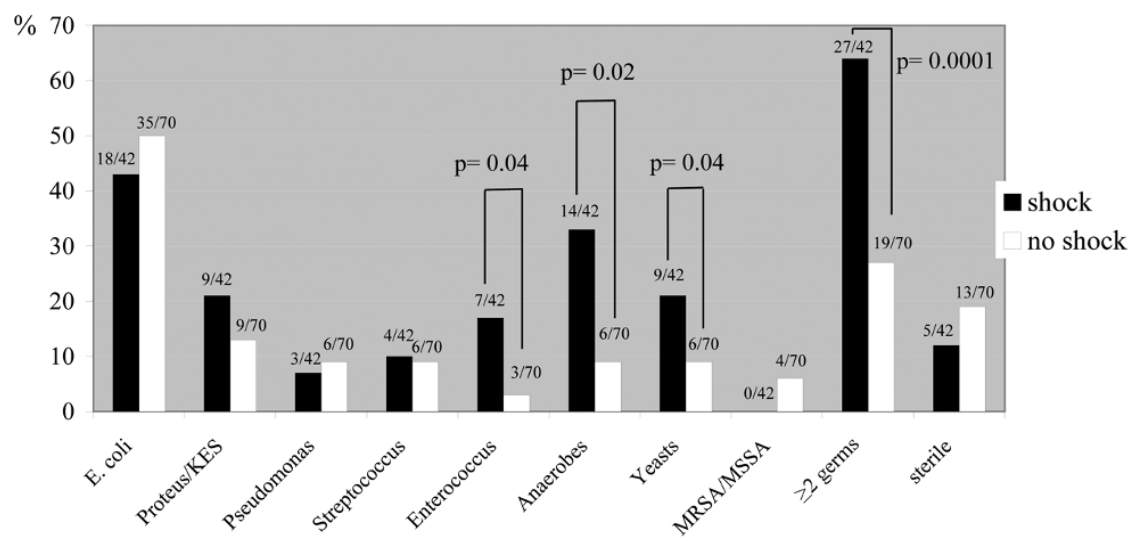

Proportion of microorganisma isolated from peritoneal fluid culture in community-acquired peritonitis with (black bars) or without (white bars) septic shock. On the top of each bar: number of patients in whom the microorganism was identified with respect to total number of patients in the subgroup (shock: $n=42$; no shock: $n=70$ ). KES = Klebsiella, Enterobacter, Serratia. MRSA/MSSA = methicillin-resistant Staphylococcus aureus/ Methicillin-sensitive Staphylococcus aureus.

experimental model of peritonitis [35]. In addition, it has been suggested that if initial antibiotic therapy does not cover for $E$. faecalis, patients have an increased risk of postoperative complications and death $[36,37]$, but contradictory results have been reported as well [38].

In our patients, yeasts were also more frequently encountered in the peritoneal fluid of community-acquired peritonitis with shock, and postoperative peritonitis with yeasts had a higher mortality rate. This confirms results of previous studies in which yeasts were associated with worse prognosis $[39,40]$, especially in the postoperative setting [10].

\section{Conclusions}

In our cohort of consecutive patients with secondary peritonitis, we observed that age greater than 65 years, two or more

\section{Figure 3}

Germs from peritoneal fluid culture in post-operative peritonitis

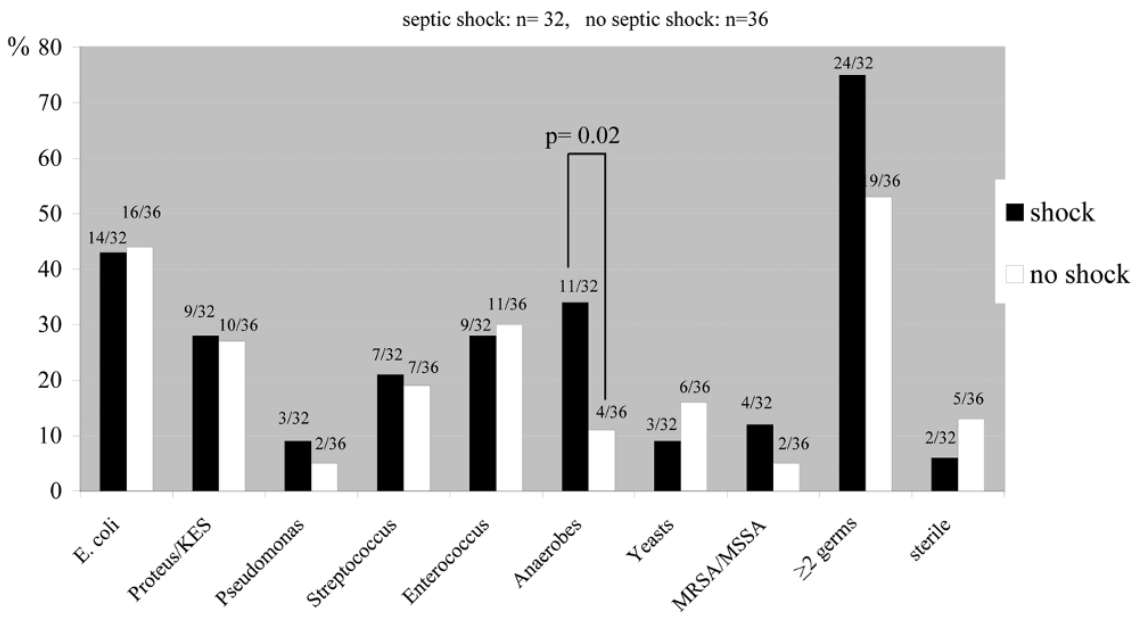

Proportion of microorganisma isolated from peritoneal fluid culture in postoperative peritonitis with (black bars) or without (white bars) septic shock. On the top of each bar: number of patients in whom the microorganism was identified with respect to total number of patients in the subgroup (shock: $\mathrm{n}=32$; no shock: $\mathrm{n}=36$ ). KES = Klebsiella, Enterobacter, Serratia. MRSA/MSSA = methicillin-resistant Staphylococcus aureus/Methicillinsensitive Staphylococcus aureus. 


\section{Figure 4}

Survival according to presence of yeasts in postoperative peritonitis (\%)

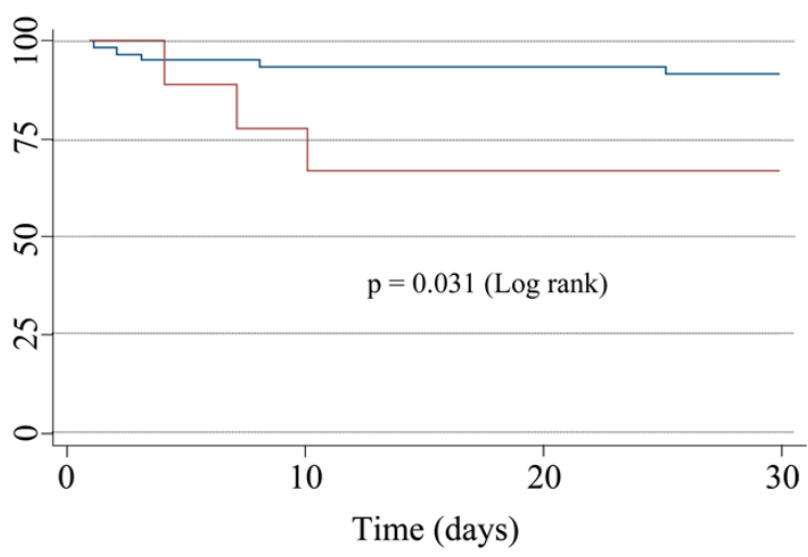

yeasts : - no yeast :

Survival according to presence of yeasts in postoperative peritonitis.

mircoorganisms isolated from peritoneal fluid, or anaerobes in peritoneal fluid were independent risk factors of septic shock. Incidence of septic shock and mortality rate were no different between patients with community-acquired and postoperative peritonitis. Intra-peritoneal yeasts and Enterococci were associated with septic shock in the subgroup of patients with community-acquired peritonitis. Yeasts were also associated with increased mortality in postoperative peritonitis. Our observations suggest that a prospective randomized trial is required to evaluate the potential benefit of systematic treatment against Enterococci and yeasts in secondary peritonitis.

\section{Key messages}

- Unlike previous reports, in this large series of patients with secondary peritonitis, we observed no difference in incidence of shock and outcome between patients with postoperative and those with community-acquired peritonitis.

- Our observations confirmed that Enterococcus and yeast in the peritoneal fluid of patients with secondary peritonitis are associated with worse outcome.

- Biliary origin of peritonitis was an independent risk factor for mortality in this cohort of 180 secondary peritonitis.

\section{Competing interests}

The authors declare that they have no competing interests.

\section{Authors' contributions}

FR contributed to conception and design, carried out data acquisition, analysis and interpretation, and drafted the manuscript. BC contributed to data analysis and interpretation, and drafted the manuscript. XD contributed to data analysis and interpretation, and participated in drafting the manuscript. MJL, JM, LR, MJSLP, DP, and PV revised the manuscript critically for important intellectual content. All authors read and approved the final manuscript.

\section{References}

1. Hotchkiss RS, Karl IE: The pathophysiology and treatment of sepsis. N Engl J Med 2003, 348:138-150.

2. Wittmann DH: Intraabdominal infections. World J Surg 1990, 14:145-147.

3. Montravers P, Gauzit R, Muller C, Marmuse JP, Fichelle A, Desmonts JM: Emergence of antibiotic-resistant bacteria in cases of peritonitis after intraabdominal surgery affects the efficacy of empirical antimicrobial therapy. Clin Infect Dis 1996, 23:486-494.

4. Roehrborn A, Thomas L, Potreck O, Ebener C, Ohmann C, Goretzki $\mathrm{P}$, Röher H: The microbiology of postoperative peritonitis. Clin Infect Dis 2001, 33:1513-1519.

5. Sotto A, Lefrant JY, Fabbro-Peray P, Tafuri J, Navarro F, Prudhomme M, De La Coussaye J: Evaluation of antimicrobial therapy management of 120 consecutive patients with secondary peritonitis. J Antimicrob Chemother 2002, 50:569-576.

6. Guillou $\mathrm{PJ}$ : Biological variation in the development of sepsis after surgery or trauma. Lancet 1993, 342:217-220.

7. Wakefield $\mathrm{CH}$, Carey PD, Foulds S, Monson J, Guillou P: Changes in major histocompatibility complex class II expression in monocytes and $T$ cells of patients developing infection after surgery. Br J Surg 1993, 80:205-209.

8. Hall J, Heel K, Papadimitriou J, Platell C: The pathobiology of peritonitis. Gastroenterology 1998, 114:185-196.

9. Bohnen J, Boulanger M, Meakins JL, McLean AP: Prognosis in generalized peritonitis. Relation to cause and risk factors. Arch Surg 1983, 118:285-290.

10. Montravers $\mathrm{P}$, Dupont H, Gauzit R, Veber B, Auboyer C, Blin P, Hennequin $\mathrm{C}$, Martin $\mathrm{C}$ : Candida as a risk factor for mortality in peritonitis. Crit Care Med 2006, 34:646-652.

11. Marshall JC: Intra-abdominal infections. Microbes Infect 2004 , 6:1015-1025.

12. Bone RC, Balk RA, Cerra FB, Dellinger RP, Fein AM, Knaus WA, Schein RM, Sibbald WJ: Definitions for sepsis and organ failure and guidelines for the use of innovative therapies in sepsis. The ACCP/SCCM Consensus Conference Committee. American College of Chest Physicians/Society of Critical Care Medicine. Chest 1992, 101:1644-1655.

13. Peto $\mathrm{R}$, Peto J: Asymptotically efficient rank invariant test procedures. J R Stat Soc Ser A 1972, 135:185-207.

14. Kay R: Goodness of fit methods for the proportional hazards regression model: a review. Rev Epidemiol Sante Publique 1984, 32:185-198.

15. Angus D, Linde-Zwirble W, Lidicker J, Clermont G, Carcillo J, Pinsky M: Epidemiology of severe sepsis in the United States: analysis of incidence, outcome, and associated costs of care. Crit Care Med 2001, 29:1303-1310.

16. Khanna K, Markham RB: A perspective on cellular immunity in the elderly. Clin Infect Dis 1999, 28:710-713.

17. Gomez RC, Boehmer DE, Kovacs JE: The aging innate immune system. Curr Opin Immunol 2005, 17:457-462.

18. Gavazzi G, Krause KH: Ageing and infection. Lancet Infect Dis 2002, 2:659-666

19. Holzheimer RG, Schein $M$, Wittmann $D H$ : Inflammatory response in peritoneal exudate and plasma of patients undergoing planned relaparotomy for severe secondary peritonitis. Arch Surg 1995, 130:1314-1319.

20. Riche F, Panis Y, Laisne MJ, Briard C, Cholley B, Bernard-Poenaru O, Graulet AM, Gueris J, Valleur P: High tumor necrosis factor serum level is associated with increased survival in patients with abdominal septic shock: a prospective study in 59 patients. Surgery 1996, 120:801-807.

21. Riche FC, Cholley BP, Panis YH, Laisne MJ, Briard CG, Graulet $\mathrm{AM}$, Gueris JL, Valleur PD: Inflammatory cytokine response in patients with septic shock secondary to generalized peritonitis. Crit Care Med 2000, 28:433-437. 
22. Onderdonk A, Weinstein W, Sullivan N, Bartlett J, Gobach S: Experimental intraabdominal abscesses in rats: quantitative bacteriology of infected animals. Infect Immun 1974, 10:1256-1259.

23. Duerden I: Virulence factors in anaerobes. Clin Infect Dis 1994, 18:253-259.

24. Styrt B, Gorbach SL: Recent developments in the understanding of the pathogenesis and treatment of anaerobic infections (1). N Engl J Med 1989, 321:240-246.

25. Styrt B, Gorbach SL: Recent developments in the understanding of the pathogenesis and treatment of anaerobic infections (2). N Engl J Med 1989, 321:298-302.

26. Rotstein O, Pruett T, Sorenson J, Fiegel V, Nelson R, Simmons R: A Bacteroides by-product inhibits human polymorphonuclear leukocyte function. Arch Surg 1986, 121:82-88.

27. Brun-Buisson $C$, Doyon F, Carlet J, Dellamonica P, Gouin F, Lepoutre A, Mercier JC, Offenstadt G, Regnier B: Incidence, risk factors, and outcome of severe sepsis and septic shock in adults. A multicenter prospective study in intensive care units. French ICU Group for Severe Sepsis. JAMA 1995, 274:968-974.

28. Dellinger RP, Levy MM, Carlet JM, Bion J, Parker MM, Jaeschke $R$ Reinhart K, Angus DC, Brun-Buisson C, Beale R, Calandra T, Dhainaut JF, Gerlach H, Harvey M, Marini JJ, Marshall J, Ranieri M, Ramsay G, Sevransky J, Thompson BT, Townsend S, Vender JS, Zimmerman JL, Vincent JL: Surviving Sepsis Campaign: international guidelines for management of severe sepsis and septic shock: 2008. Intensive Care Med 2008, 34:17-60.

29. Walker $\mathrm{E}$, Elis $\mathrm{H}$ : Relationship of the constituents of bile to biliary peritonitis in the rat. Gut 1978, 19:827-831.

30. Anderson R, Sonesson A, Larsson L, Sclalen C, Tranberg K: Bile increases lipopolysaccharide release in experimental $\mathrm{E}$. Coli peritonitis. Eur J Surg 1991, 157:117-120.

31. Anderson R, Tranberg K, Bengmark S: Role of bile and bacteria in biliary peritonitis. Br J Surg 1990, 77:36-39.

32. Koperna T, Schulz F: Prognosis and treatment of peritonitis. Do we need new scoring systems? Arch Surg 1996, 131:180-186.

33. Dupont $\mathrm{H}$, Carbon $\mathrm{C}$, Carlet J: Monotherapy with a broad-spectrum beta-lactam is as effective as its combination with an aminoglycoside in treatment of severe generalized peritonitis: a multicenter randomized controlled trial. The Severe Generalized Peritonitis Study Group. Antimicrob Agents Chemother 2000, 44:2028-2033.

34. Solomkin JS, Yellin AE, Rotstein OD, Christou NV, Dellinger EP Tellado JM, Malafaia O, Fernandez A, Choe KA, Carides A, Satishchandran V, Teppler $\mathrm{H}$ : Ertapenem versus piperacillin/tazobactam in the treatment of complicated intraabdominal infections: results of a double-blind, randomized comparative phase III trial. Ann Surg 2003, 237:235-245.

35. Montravers $\mathrm{P}$, Andremont A, Massias L, Carbon C: Investigation of the potential role of Enterococcus faecalis in the pathophysiology of experimental peritonitis. J Infect Dis 1994, 169:821-830.

36. Montravers P, Mohler J, Saint Julien L, Carbon C: Evidence of the proinflammatory role of enterococcus faecalis in polymicrobial peritonitis in rats. Infect Immun 1997, 65:144-149.

37. Sitges-serra A, Lopez M, Girvent M, Almirall S, Sancho J: Postoperative enterococcal infection after treatment of complicated intra-abdominal sepsis. Br J Surg 2002, 89:361-367.

38. Rohrborn A, Wacha H, Schoffel U, Billing A, Aeberhard P, Gebhard B, Bocker I, Schafer V, Ohmann C: Coverage of enterococci in community acquired secondary peritonitis: results of a randomized trial. Surg Infect (Larchmt) 2000, 1:95-107.

39. Calandra T, Bille J, Schneider R, Mosimann F, Fancioli P: Clinical significance of Candida isolated from peritoneum in surgical patients. Lancet 1989, 2:1437-1440.

40. Dupont H, Paugam-Burtz C, Muller-Serieys C, Fierobe L, Chosidow D, Marmuse J, Mantz J, Desmonts J: Predictive factors of mortality due to polymicrobial peritonitis with Candida isolation in peritoneal fluid in critically ill patients. Arch Surg 2002, 137:1341-1346. 